\title{
A Comparative Study of Entrepreneurial Supporting Policies in China's Various Regions
}

\author{
Min Qian ${ }^{1, a,}$, Tingting Wang ${ }^{1, b}$ \\ ${ }^{1}$ School of Economic \& Management ,Nanjing University of Science and Technology, Xuanwu \\ Street, Nanjing Town, China \\ ${ }^{2}$ School of Economic \& Management ,Nanjing University of Science and Technology, Xuanwu \\ Street, Nanjing Town, China \\ a1684356170@qq.com, b wangtingtingllf@163.com \\ * Tingting Wang
}

\begin{abstract}
In today's public innovation, entrepreneurship atmosphere, college students set off an upsurge of entrepreneurship. Local governments are also actively responding to the policies of the Central Government and formulating their local policies on starting a business, taking into consideration only the development status and characteristics of the area. This study summarizes the degree of entrepreneurial activity in various regions of China and finally chooses five cities with different degrees of activity as the representatives of low entrepreneurial activity (Tibet), China (Changsha, Nanjing) and Gao (Shenzhen, Shanghai) respectively . Five regions gave concrete support policies for college students to start their undertakings, conducted comparative analysis, probed into the causes of different policies at the same time, and put forward suggestions and countermeasures in order to better implement the policy of starting their own businesses.
\end{abstract}

Keywords: Different regions, entrepreneurship, support policies.

\section{Background}

Government start-up support policy is to promote college students an important force. In recent years, local government at all levels hope to improve and optimize the entrepreneurial environment of undergraduates by encouraging and supporting the policies of entrepreneurship, motivate the graduates to start their own businesses, and achieve the multiplier effect of taking jobs as a starting point. In 2009, the self-employed rate of college students in our country was only $1.94 \%$, and the successful rate of entrepreneurship was less than $10 \%$. In stark contrast, college students in Europe and America self-employment rate reached 20\% -30\%. The government will undoubtedly improve this situation through the gradual implementation and improvement of the entrepreneurship policy. Based on the relevant policies that have been promulgated in Shanghai, Hangzhou and Changsha, which have done a good job in starting up the entrepreneurial support for college students, this article compares and classifies the policies of the three places in order to provide some reference to the local government in formulating policies to support the entrepreneurship of undergraduates.

Entrepreneurship policy is concerned about the beginning of the 1990s, the main theoretical achievements focus on the basic connotation of entrepreneurship policy and entrepreneurship policy framework on the building. Although entrepreneurial policies are highly valued both at home and abroad, the existing research is still in its infancy, and there is still a lack of systematic theoretical research.

Policy-based financing support refers to providing various kinds of financing and subsidies to start-ups based on government policies and solving venture capital financing problems, including loan guarantees, gratis subsidies, credit guarantees, matching subsidies and loan interest subsidies. 
Tax concessions and regulatory environment support refer to the promotion of more entrepreneurship by reducing the entrepreneurial costs, by providing tax relief to entrepreneurs, by giving tax breaks to prescribed industries, and by lowering system requirements. Mainly involved in the tax relief for entrepreneurs for a certain period of time, tax incentives for specific industries, reduce the registered capital requirements, reduce site restrictions and so on.

Entrepreneurial service is to provide entrepreneurs with a series of entrepreneurial support directly related to entrepreneurship. Mainly to simplify procedures, providing guidance for the opening, entrepreneurial mentor help, entrepreneurial team exchange, entrepreneurship education and training.

\section{Comparison of Entrepreneur Support Policies of Five University Students in Changsha, Nanjing, Shenzhen and Shanghai}

\subsection{Policy financing support}

Policy financing support is a very important part of entrepreneurship support policy, which can alleviate the financial pressure of college entrepreneurs' entrepreneurship in the initial stage and increase the financing channels backed by government credit. In general, Nanjing is well-equipped with policy-based financing to cover all aspects of administrative fees, social insurance subsidies, gratis subsidies, secured loans and fiscal discounts. In initial venture social insurance subsidies, both Shenzhen and Shanghai stipulate the subsidy period of no more than 3 years; Nanjing subsidizes them according to the enterprise's development prospect and sub-standard; and Tibet has the largest subsidy and subsidies for a total of 10 years. One-time entrepreneurship subsidies and grants, Nanjing and Shenzhen have great support for outstanding projects, especially in Nanjing subsidies between 20-50 million, and there is some supporting support. In terms of secured loans, Changsha and Nanjing each have a quota of 500,000 for partnerships, and Nanjing has a higher limit for individual companies than Changsha, but Changsha has a larger supportive policy for start-ups.

\subsection{Tax incentives and regulatory environment support}

Tax incentives and environmental regulation support the government to reduce business start-up costs and reduce the market access threshold an effective means. In general, tax concessions throughout the period are mostly for a period of three years; Changsha can grow another good project for another two years. In terms of the preferential treatment, Changsha earns a portion of the local income tax deducted from sales tax and personal income tax; each household in Tibet has an annual quota of 10,000; and each household in Nanjing uses 9600 a year, but Nanjing and Shanghai have additional preferential treatment for enterprises that recruit unemployed persons. In terms of registered capital, Shenzhen and Shanghai implemented the "zero down payment" of registered capital.

\subsection{Venture venues and cost support}

Entrepreneurial venues and cost support not only directly reduce the economic burden of college students start-up period, but also through the establishment of college students start-up business parks for college students to learn from each other to create groups of brands, reduce matching costs and create entrepreneurial atmosphere and other agglomeration effects . In this respect, the design policies of the five places are similar in design. All of them have some subsidies or reliefs on the rent of start-up venues; and the reduction of relief within the start-up bases is higher than that of bases. However, the subsidy levels varied from place to place. Among them, Shenzhen topped the list. Most of the fees for the exemption of administrative fees and charges are based on a three-year limit. Tibet provides certain living subsidies to entrepreneurs. In particular, in order to attract outstanding college students to start their own businesses in Changsha, they provided free start-up flats or dormitories and formulated low-rent housing policies.

\subsection{Business service content}

Entrepreneurship services more extensive, covering the three elements of opportunity, motivation and skills areas. Entrepreneurs all over the world have provided a large number of entrepreneurial support services, such as the construction of entrepreneurial incubator park, business services platform; provide entrepreneurial training services, consulting services experts; and talent 
introduction plan. Entrepreneurial services in encouraging and supporting college students is indispensable. How to coordinate the functions of various government departments under the existing system and how to guide the intermediary organizations to participate enthusiastically will directly affect the implementation of these policies in the implementation process.

\section{Conclusion}

Over the years, the state policy environment has emphasized the great development of the western region and the development of the western region as the goal of the east. Therefore, Tibet and other places give more support to college students to start their own businesses.

Local government to develop and support college students entrepreneurship policy, inevitably with the local social and economic development at the time closely integrated positioning. Different policy orientation, the focus of its policy content will be different. Local government support policy target groups are limited to local college students, or to benefit all the local business students, both with the social and economic development around the positioning, but also with the college students business in the local social and economic development in the overall expectation.

The current government-specific grants for unpaid grants and loan discounts are directly affected by the ability of local governments to make fiscal payments on the scale and sustainability of policy-financed policies. Tax incentives are subject to the existing tax system, but also by the tax revenue of local governments. In the policy package, fiscal and tax policy support is undoubtedly the most direct and most effective results. However, the long-term implementation of this policy will continue to increase the government's financial burden. Therefore, to improve the success rate of college students to start a business, improve business performance of start-ups, and expand the new tax sources, is the key to sustaining the supporting policies. Supporting the establishment of Pioneering Park for Students can not only solve the problem of establishing start-ups for undergraduates, but also provide various training and incubation services for start-ups and introduce various investment funds and social intermediary services to improve the success rate of entrepreneurship. This is a relatively effective measure to date, and to a certain extent, it has also avoided the embarrassment of relying solely on sustained government funding. How to do a good job of college students Pioneering Park has become an important part of building up a supportive college student entrepreneurship policy system in these three places.

Independent entrepreneurship is one of the ways for new entrepreneurs to grow up in the course of economic restructuring and upgrading, and it is also one of the important fields for the development of private economy in the future. The formulation and improvement of college students' starting-up support policies are the inevitable requirements of economic development to a certain stage. However, the special support policies for college students' entrepreneurial groups will be constrained by the existing institutional and local government's supply of resources. Therefore, how to evaluate the social performance of college students' entrepreneurial undertakings, how to create an atmosphere of caring for and supporting the undertaking of college students, mobilizing more social resources to join the undertaking of undertaking college students, enhancing the matching of supporting policies and improving the effectiveness of supporting policies is yet to be realized Further exploration and improvement of the subject. University student density. The density of local college students will affect the annual net inflow of government personnel, so in order to attract talent to introduce different policies. For example, the number of colleges and universities in remote areas is relatively small. In order to attract more talents, the government should provide more vigorous policies.

In order to better implement the government's policy of starting a business, and create a good entrepreneurial atmosphere, put forward the following suggestions: The establishment of a business park. Supporting the establishment of Pioneering Park for Students can not only solve the problem of establishing start-ups for undergraduates, but also provide various training and incubation services for start-ups and introduce various investment funds and social intermediary services to improve the success rate of entrepreneurship. Mobilize the overall social resources and forces, business services, including both the government for college students start some special services, but also includes a 
variety of services for all SMEs. How the government mobilizes and organizes more social intermediaries to join the support services for college students is an important symbol of the strong entrepreneurial atmosphere of local college students and an important measure to continuously support the entrepreneurship of college students. Effective evaluation of entrepreneurial performance, entrepreneurial groups of college students special support policies will be subject to the constraints of the existing institutional and local government resources. Therefore, how to evaluate the social performance of college students' entrepreneurial undertakings, how to create an atmosphere of caring for and supporting the undertaking of college students, mobilizing more social resources to join the undertaking of undertaking college students, enhancing the matching of supporting policies and improving the effectiveness of supporting policies is yet to be realized Further exploration and improvement of the subject.

\section{References}

[1] Liu, Cengceng, N. Li, and D. Zha. "On the impact of FIT policies on renewable energy investment: Based on the solar power support policies in China's power market." Renewable Energy 94(2016):251-267.

[2] Gu, Shulin. "Institutional entrepreneurship and policy learning in China." Journal of Science \& Technology Policy in China 4.1(2013):36-54(19).

[3] Mei, Ciqi, Chen, Kang, and Wu, Xun. "Local Government Entrepreneurship in China: A Public Policy Perspective." China An International Journal 14.3(2016):2016.

[4] Zhu, Xufeng. "In the name of 'Citizens': civic activism and policy entrepreneurship of Chinese public intellectuals in the Hu-Wen era." Journal of Contemporary China 25.101(2016):1-15.

[5] James Liang. "Will one child policy reduce entrepreneurship in China?." China Economic Journal 5.2-3(2012):85-95.

[6] Li, Changhong, et al. "Policies of promoting entrepreneurship and Angel Investment: Evidence from China." Emerging Markets Review 29(2016):154-167.

[7] Zhu, Yapeng. "Policy Entrepreneur, Civic Engagement and Local Policy Innovation in China: Housing Monetarisation Reform in Guizhou Province." Australian Journal of Public Administration 71.2(2012):191-200.

[8] Hammond, Daniel R. "Policy Entrepreneurship in China's Response to Urban Poverty." Policy Studies Journal 41.1(2013):119-146.

[9] Peng, Xuebing, G. Zhang, and J. Li. "Technological entrepreneurship and policy environment: a case of China." Journal of Small Business \& Enterprise Development 15.4(2008):733-751.

[10]Warnecke, Tonia. "Are we fostering opportunity entrepreneurship for women? Exploring policies and programmes in China and India." International Journal of Entrepreneurship \& Innovation Management 18.2/3(2014):154-181.

[11] Xu, Xiaozhou. "Analysis of national policies for entrepreneurship education in China." Globalisation Societies \& Education 10.3(2012):403-420.

[12]Wonglimpiyarat, J. "Equity financing and capital market funding policies to support entrepreneurial development in Asia: Comparative cases of Thailand, Malaysia, Singapore, and Taiwan." Journal of Private Equity 15.4(2012):10-24.

[13]Cai, Li, et al. "Market orientation and technological innovation: the moderating role of entrepreneurial support policies." International Entrepreneurship \& Management Journal 11.3(2015):645-671. 